\title{
UV SPECTROPHOTOMETRIC, DERIVATIVE SPECTROPHOTOMETRIC AND RP-HPLC-DAD DETERMINATION OF SIBUTRAMINE
}

\author{
Gokce Kilicarslan ${ }^{1}$, Esin Imamoglu ${ }^{1}$, Aysel Kucuk ${ }^{1},{ }^{*}$ Abdil Ozdemir ${ }^{1}$ \\ 'Department of Chemistry, Faculty of Arts and Sciences, \\ Sakarya University, Esentepe Campus, 54187, Sakarya, Turkey
}

\begin{abstract}
Simple and rapid new methods were developed and validated as an alternative to the quantification methods of sibutramine presented in the literature. UV-Vis. and derivative spectrophotometry methods were based on the determination of sibutramine pharmaceutical preparations (capsule dosage forms) in different solvent media (methanol and water). All UV-Vis. absorbance spectra of sibutramine were recorded with maximum absorbance of $224 \mathrm{~nm}$ and with spectral bandwidth of $2 \mathrm{~nm}$ and all first- and secondorder derivative spectra of sibutramine were recorded at 217 and $223 \mathrm{~nm}$ with spectral bandwidth of $5 \mathrm{~nm}$ in wavelength range of $200-400 \mathrm{~nm}$ in methanol and water media. The other method was a new RP-HPLC with DAD detector method developed for the determination of sibutramine by using Donepezil as the internal standard in human plasma samples (in-vitro) and in pharmaceutical preparations (capsule dosage forms). HPLC was performed using mobile phase comprising of methanol-acetonitrile (90:10) on a reversed phase $C_{18}$ column and the detection was carried out at $224 \mathrm{~nm}$. The recovery of capsule by standard addition method was found to be in the range of 101.10-104.08\% and 91.96-107.68\%, respectively. The developed methods were applied directly and easily to the analysis both of pharmaceutical preparations and biological fluids without extraction or evaporation steps prior to drug assays. Also bioanalytical method validation was achieved

"Corresponding Author:

e-mail: ayselk@sakarya.edu.tr
\end{abstract}


successfully for comparison as statistical of developed methods both in pharmaceutical preparations and plasma levels in vivo outside, and validation results on linearity, specificity, accuracy and precision were effectively performed.

Keywords: Sibutramine, UV-Vis. Spectrophotometry, Derivative Spectrophotometry, High Performance Liquid Chromatography

\section{INTRODUCTION}

Sibutramine hydrochloride is an orally administrated agent for the treatment of obesity. Its expected activity is weight loss through inhibition of serotonin and norepinephrine reuptake $/ 1 /$. It is chemically a racemic mixture of the (+) and (-) enantiomers. The chemical name of sibutramine is $\mathrm{N}-\{1,-$ [1-(4-chlorophenyl)-cyclobutyl]-3-methylbutyl\}-N,N-dimethylamine hydrochloride monohydrate (Figure 1) and it has an empirical formula of $\mathrm{C}_{17} \mathrm{H}_{29} \mathrm{C}_{12} \mathrm{NO} / 2 \%$.

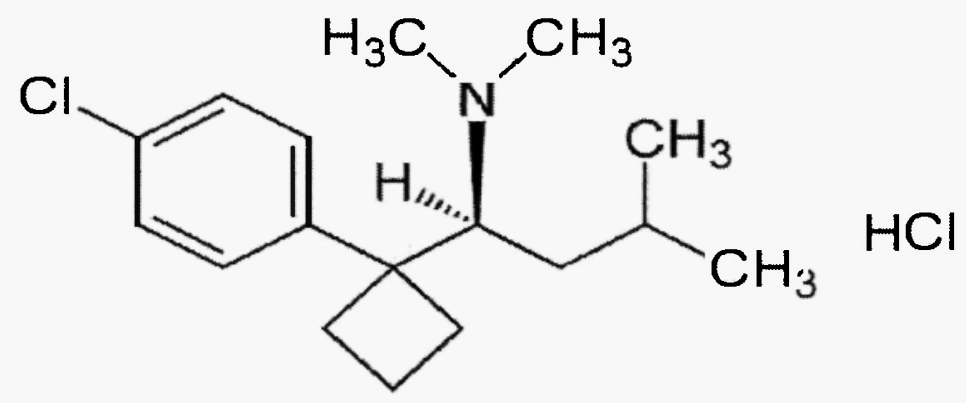

Fig. 1: Chemical structure of sibutramine

Based on the literature review, a number of analytical methods such as UV-Vis. $/ 3,4 /$, GC-MS $/ 5,6 /$, LC-ESI-MS /7,8/], LC-ESI-TMS /9-11/, HPLCUV /12-15/, Chiral LC for enantiometric separation /16/, HPLC-UV using column-switching in rat serum $/ 17 /$ etc. have been developed for determination of sibutramine but no method has been developed so far in the literature for determination of sibutramine hydrochloride by using RP-HPLC method with DAD detection in human plasma and no derivative spectrophotometric method in capsule dosage forms for different solvent 
media (methanol and water).

The proposed methods are cheaper and simpler than other methods. It might be an alternative to other HPLC techniques by using simple mobile phase for routine analysis in human plasma and there are no extraction processes to eliminate the excipients, which are time consuming and tedious. Another important advantage of these proposed techniques over the other techniques can be applied directly to the analysis of pharmaceutical dosage forms and biological samples without the need for extensive sample preparation, since there was no interference from the excipients and endogenous substances. Quantitation was accomplished by using an internal standard method. This study was conducted in order to develop a new RPHPLC method of shorter analysis time and a detailed comparison of HPLC method was carried out by UV and derivative spectrophotometric method in capsules.

\section{EXPERIMENTAL}

\subsection{Instrumentation}

For spectrophotometric study, Shimadzu UV-2401 PC Model, UV-Vis Recording Spectrophotometer, in a $10-\mathrm{mm}$ quartz cells were connected to (LG) PC Computer and Hewlett-Packard DeskJet printer and Momentum SVC-1000 regulator.

For chromatographic study, a Shimadzu mark HPLC system with a SPDM20A Prominence photodiode array detection system consisting of LC20AD Prominence Liquid Chromatography, SIL-20A HT Prominence auto sampler, DGU-20A5 Prominence degasser, CTO-10AS VP Column Oven, LC Solution Program, were connected to Samsung Computer and FCM power source.

\subsection{Materials and Reagents}

Certificated Sibutramine standard was obtained from Fargem A.S. (Turkey). Donepezil used as internal standard was donated from a Turkish pharmaceutical industrial firm. The commercial capsules (Reductil, $15 \mathrm{mg}$ ) containing the active ingredient sibutramine were kindly supplied by Turkish distributor under license from Abbott Lab. The plasma sample was obtained 
from a healthy volunteer in Istanbul-Turkey. All other chemicals were analytical grade and HPLC grade (Merck, Germany).

\subsection{Spectroscopic Conditions and Optimisation}

All of the UV absorbance spectra of sibutramine were obtained with the spectral bandwidth of $2 \mathrm{~nm}$ by scanning wavelength range of $200-400 \mathrm{~nm}$ in methanol and water media. In these conditions, a single well-defined maximum peak was monitored and no difference was observed in the maximum wavelengths of all spectra for both solvent media $(n=6)$. All of the absorbance measurements and absorbance spectrums of samples contained commercial capsules were taken at a wavelength of $224 \mathrm{~nm}$ for methanol and water, respectively (Figure $2 \mathrm{a}-2 \mathrm{~b}$ and Figure $3 \mathrm{a}-3 \mathrm{~b}$ ).

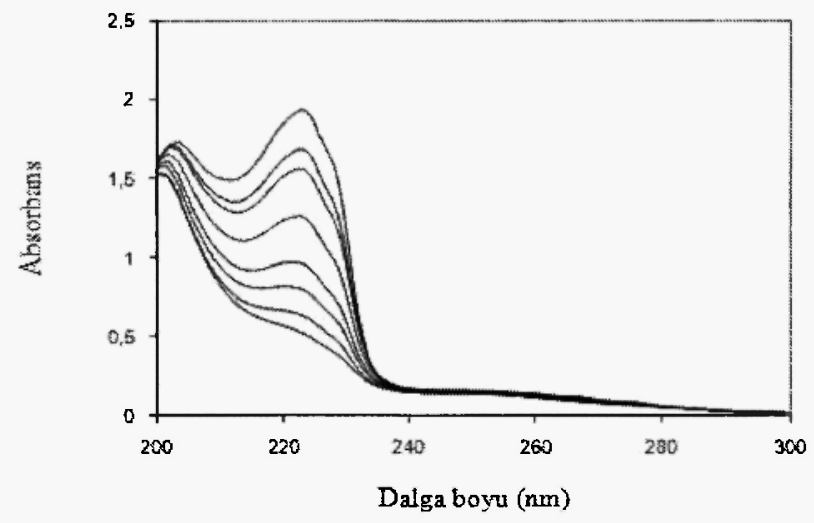

Fig. 2a: UV absorbance spectrums of sibutramine in methanol

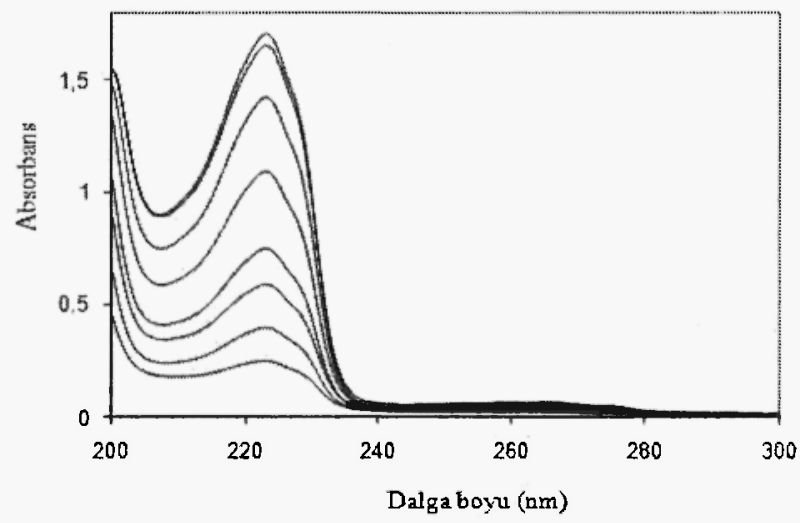

Fig. 2b: UV absorbance spectrums of sibutramine in water 

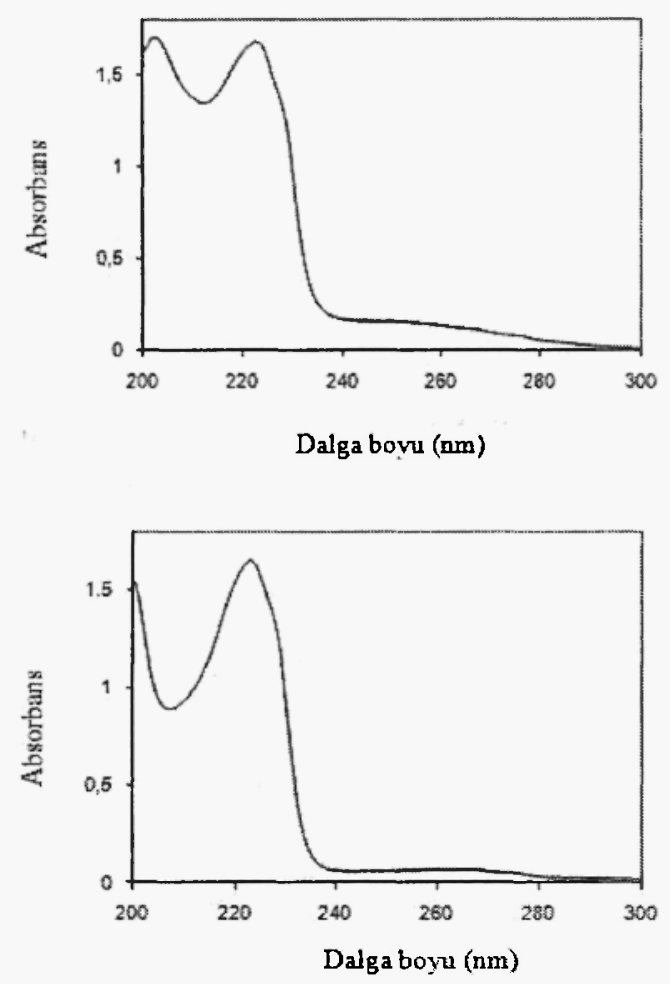

Fig. 3a and 3b: UV absorbance spectrums of samples contained commercial sibutramine capsules of $45 \mu \mathrm{g} \mathrm{mL}^{-1}$ in methanol and water, respectively.

All of the derivative absorbance spectra of sibutramine were obtained with $5 \mathrm{~nm}$ instead of the spectral bandwidth of $2 \mathrm{~nm}$ scanning wavelength range of $200-400 \mathrm{~nm}$ in methanol and water media. The first-order curve was displayed one maximum at $217 \mathrm{~nm}$ and one minimum at 230 and (in Figure 4a and 5a), while the second-order curve was showed one maximum at 223 $\mathrm{nm}$ and one minimum at $232 \mathrm{~nm}$ in both solvent media (in Figure $4 \mathrm{~b}$ and $5 \mathrm{~b}$ ). The largest ones of which would be more sensitive were preferred by comparing the regression coefficients and the slopes from calibration curves. So, the absorbance values obtained of wavelengths at 217 and $223 \mathrm{~nm}$ were taken. The reason of quantification for sibutramine with derivative spectroscopy was to determinate better of the peak shapes and to eliminate possible impurities. Since water is more a polar solvent (forming the H-bond) 
than methanol, the detail structures do not appear. The polarity of methanol is lower than water and its dipole-dipole and dielectric effects are not present. Because of this, the refined structures are seen in more detail.

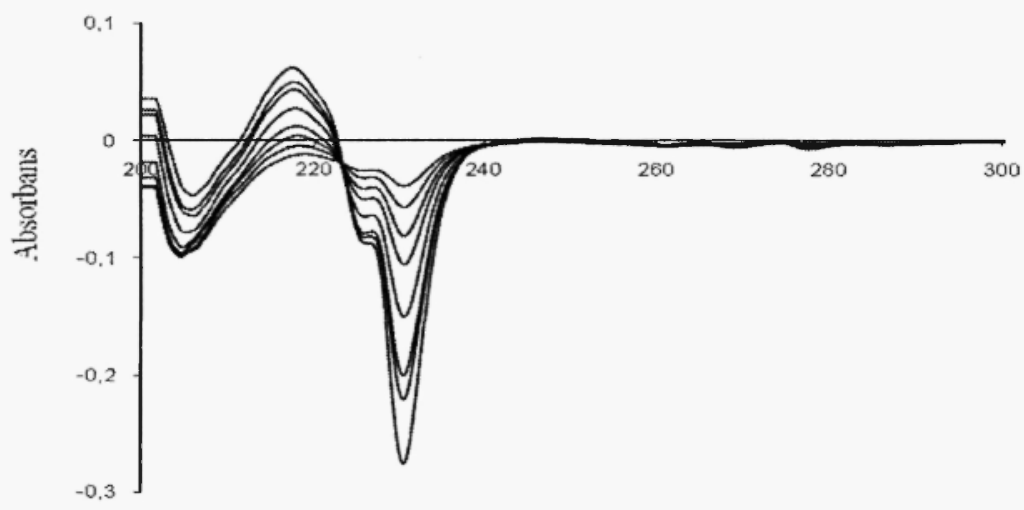

Dalga boyu (nm)

Fig. 4a: First-order derivative spectrums of sibutramine in methanol medium $\left(5,10,15,20,30,40,45\right.$ ve $\left.50 \mu \mathrm{g} \mathrm{mL}^{-1}\right)$

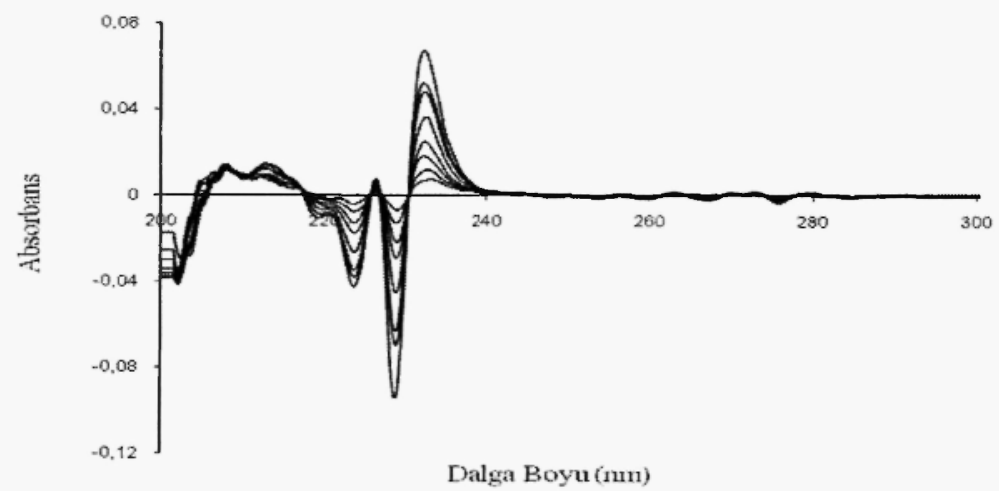

Fig. 4b: Second-order derivative spectrums of sibutramine in methanol medium $\left(5,10,15,20,30,40,45\right.$ ve $\left.50 \mu \mathrm{g} \mathrm{mL}{ }^{-1}\right)$ 


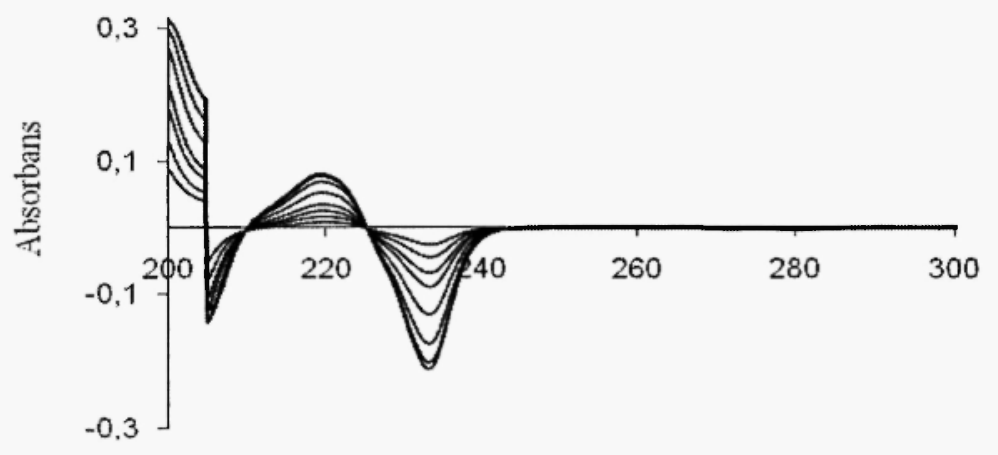

Dalga Boyu (nm)

Fig. 5a: First-order derivative spectrums of sibutramine in water mediun $\left(5,10,15,20,30,40,45\right.$ ve $\left.50 \mu \mathrm{g} \mathrm{mL}^{-1}\right)$

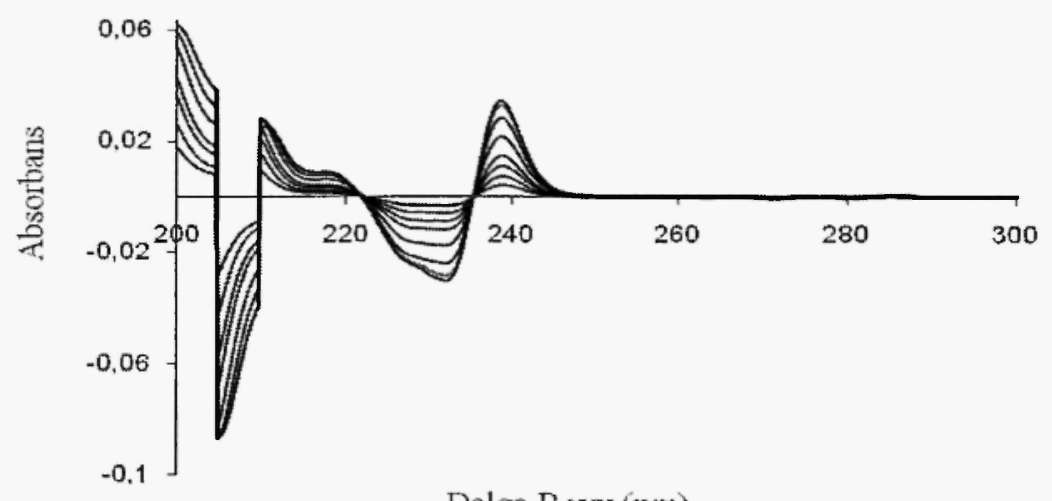

Dalga Boyu (nm)

Fig. 5b: Second-order derivative spectrums of sibutramine in water medium $\left(5,10,15,20,30,40,45\right.$ ve $\left.50 \mu \mathrm{g} \mathrm{mL}^{-1}\right)$

\subsection{Chromatographic Conditions and Optimisation}

It was determined by using isocratic pump system for developed HPLC method and scanning the region between $200-400 \mathrm{~nm}$ by using DAD detector that sibutramine showed maximum absorbance at $224 \mathrm{~nm}$. Chromatograms were obtained separately at each wavelength of $212,224,229,254,256$ and $271 \mathrm{~nm}$ and then, all chromatograms were recorded as optimal wavelength at 
$224 \mathrm{~nm}$. A 4.6x150 mm I.D. Inertsil ODS-2 reversed-phase $C_{18}$ column with a particle size of $5 \mu \mathrm{m}$ was employed. The temperature of column oven was operated at $25^{\circ} \mathrm{C}$. The flow-rate was set at $1 \mathrm{~mL} \mathrm{~min}^{-1}$. All standard samples were filtered through a membrane of $0.45-\mathrm{mm}$ pore size before injection into the HPLC system. The injection volume was $15 \mu \mathrm{L}$. Retention time (RT) was determined as $4.52 \mathrm{~min}$ for sibutramine and as $2.87 \mathrm{~min}$ for the internal standard from chromatograms obtained in these conditions (in Figure 6). The mobile phase was also optimized by using different percentage combinations such as methanol-phosphate buffer, acetonitrile-phosphate buffer, methanolacetonitrile $(50: 50,55: 45,60: 40,65: 35,70: 30,75: 25,80: 20,85: 15,90: 10$ etc.). As a result of the different mobile-phase trials, the most appropriate isocratic mobile phase was determined as a mixture of methanol-acetonitrile mixture in the ratio 90:10. Mobile phase was prepared as fresh daily and all other organic solvents were used filtering through a $0.47-\mu \mathrm{m}$ nylon membrane filter after vacuum and degassed ultrasonically before use. So, optimum conditions were chosen for the HPLC system.

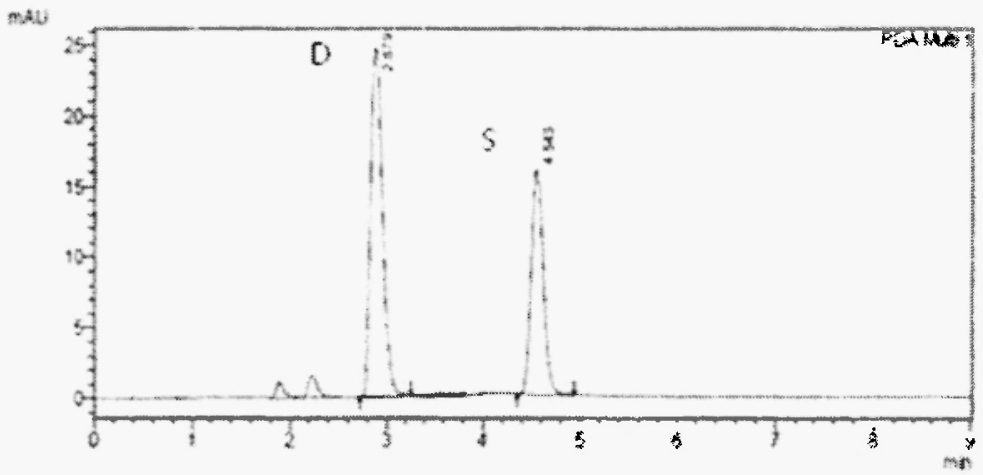

Fig. 6: Sibutramine chromatogram of $30 \mu \mathrm{g} \mathrm{mL}^{-1}$ (with added Donepezil of $15 \mu \mathrm{g} \mathrm{ml}^{-1}$ )

Using the parameters optimized, system suitability parameters were calculated: The capacity factors as the retention functions of the peaks for sibutramine and donepezil in flow rate of $1 \mathrm{~mL} \mathrm{dk}^{-1}, \mathrm{k}_{\mathrm{s}}{ }^{\prime}: 1.82$, and $\mathrm{k}_{\mathrm{D}}{ }^{\prime}: 0.24$, the selectivity coefficient, $\alpha: 3.97$, the total theoretical plate number as an indicator of column efficiency, $\mathrm{N}$ : 2663 , the resolution as the separation power of column, $R_{\mathrm{S}}: 3.07$ and the plate height, $\mathrm{H}: 5.63 .10^{-3} \mathrm{~cm}$. the parameters were compared against those recommend by the Center for Drug Evaluation and Research (CDER) [18]. 


\subsection{Preparation of Stock and Standard Solutions}

Stock solutions of sibutramine for UV and derivative determinations were prepared as $100 \mu \mathrm{g} \mathrm{mL^{-1 }}$ in methanol and deionized water from pure sibutramine standard and kept stored at $4^{\circ} \mathrm{C}$ until used. The stock solutions were stable at least 4 weeks when stored at $4^{\circ} \mathrm{C}$. No change in the stability of the stock solutions over one month was observed. The standard solutions in $5-50 \mu \mathrm{g} \mathrm{mL}{ }^{-1}$ concentrations $\left(5,10,15,20,30,40,45\right.$ and $\left.50 \mu \mathrm{g} \mathrm{mL}^{-1}\right)$ were prepared by diluting from the stock solutions to a constant volume with methanol and water (Figure 2a and 2b). Calibration curves were prepared for eight different concentrations $(n=6)$. The quality control samples were also prepared at 15,30 and $45 \mu \mathrm{g} \mathrm{mL}^{-1}$ concentrations from stock solutions. Methanol and deionized water was used as reference in all measurements of UV and derivative spectrums.

Stock solution of sibutramine for HPLC determination was prepared as $250 \mu \mathrm{g} \mathrm{mL}^{-1}$ in mobile phase and kept stored at $4^{\circ} \mathrm{C}$ until used. The stock solution was stable about 4 weeks when stored at $4^{\circ} \mathrm{C}$. No change in the stability of the stock solution about one month was observed. The standard solutions in concentrations between $5-30 \mu \mathrm{g} \mathrm{mL}^{-1}(5,10,15,20,25$ and 30 $\mu \mathrm{g} \mathrm{mL}^{-1}$ ) for calibration curve method were prepared by diluting from the stock solutions to a constant volume with mobile phase (Figure 6). Calibration curve was prepared for six different concentrations $(n=6)$. Internal standard solution of $1 \mathrm{~mL}\left(15 \mu \mathrm{g} \mathrm{mL} \mathrm{L}^{-1}\right)$ was added on each of these standards prepared from the main stock.

New standard solutions were prepared in the range of 5-30 $\mu \mathrm{g} \mathrm{mL}^{-1}$ concentrations $\left(5,7.5,10,12.5,15,17.5,20,25\right.$ and $\left.30 \mu \mathrm{g} \mathrm{m}^{-1}\right)$ from same stock solution for recovery works in HPLC. Internal standard solution of 1 $\mathrm{mL}$ was added on each of these new nine different standards prepared and they were completed to $25 \mathrm{~mL}$ with mobile phase. A new calibration curve was prepared for nine different concentrations $(n=6)$. All standard solutions were kept stored in the refrigerator at $4{ }^{\circ} \mathrm{C}$ until used. Then, they were brought to room temperature before use and mixed with the vortex about 510 minutes.

\subsection{Pharmaceutical Sample Preparation}

Stock sample solutions of $150 \mu \mathrm{g} \mathrm{mL} \mathrm{m}^{-1}$ for $\mathrm{UV}$ and derivative determinations were prepared in two different solvent media (methanol and 
water) from the commercial capsule containing the active ingredient of $15 \mathrm{mg}$ sibutramine hydrochloride. Capsules were mixed for 5-10 minutes mixed with a vortex until thoroughly dissolved. Then capsule standard solutions were prepared by diluting in both solvent media by taking parts of 15,30 and $45 \mu \mathrm{g} \mathrm{mL}^{-1}$ from these stocks (Figure $3 \mathrm{a}$ and $3 \mathrm{~b}$ ). These samples were used in the daily analysis.

Stock sample solution of $150 \mu \mathrm{g} \mathrm{mL}{ }^{-1}$ for HPLC determination was prepared in mobile phase solvent media from the commercial capsule containing the active ingredient of $15 \mathrm{mg}$ sibutramine hydrochloride. Capsules were mixed for 5-10 minutes mixed with a vortex until thoroughly dissolved. Then, six different drug standard solutions were prepared by diluting in mobile phase solvent media by taking parts of $15 \mu \mathrm{g} \mathrm{mL}^{-1}$ from this stock. Internal standard solution of $1 \mathrm{~mL}$ was added on each of these six capsule standards prepared and they were completed with mobile phase (Figure 7). These samples were used in the daily analysis.

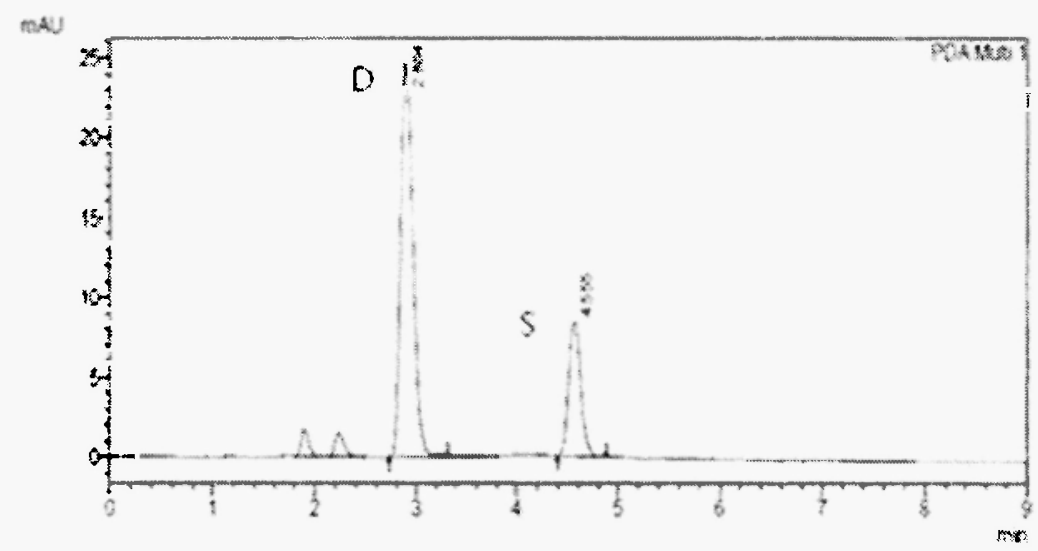

Fig. 7: Commercial sibutramine capsule chromatogram of $15 \mu \mathrm{g} \mathrm{mL}^{-1}$

\subsection{Preparation of Standards with Standard Addition Method}

In order to detect interactions of excipients (potential interfering compounds), the standard addition method was applied in HPLC. The parts of $2.5,5,7.5,10$ and $12.5 \mu \mathrm{g} \mathrm{mL}^{-1}$ from sibutramine stock solution were added into five separate flasks. Then, the parts of 2.5, 5, 7.5, 10 and $12.5 \mu \mathrm{g}$ $\mathrm{mL}^{-1}$ from commercial capsule stock solution were added into the same flasks 
and each of the standards was achieved to be total $15 \mu \mathrm{g} \mathrm{mL}^{-1}$. Also, internal standard solution of $1 \mathrm{~mL}$ was added into the same flasks and then all standards were diluted with methanol.

\subsection{Preparation of Plasma Standard Samples}

Frozen drug-free human plasma sample was left on the bench to thaw naturally at room temperature and was vortexed prior to its use. Plasma standard solutions for HPLC determination (in vitro) were prepared by spiking into drug-free human plasma with different working standard solutions, which all standards were then further diluted with methanol to give final concentrations of between 5 and $30 \mu \mathrm{g} \mathrm{mL} \mathrm{m}^{-1}$ concentrations of sibutramine (Figure 8). Also, internal standard solution of $1 \mathrm{~mL}$ was added into each of human plasma samples. All plasma standards were mixed by vortex for 50-10 min. The parts taken into the centrifuge tubes from these standards were obtained by centrifugation at $5000 \mathrm{rpm}$ for $20-30 \mathrm{~min}$. Thus, all plasma samples were so easily prepared without any extraction procedure for routine analysis.

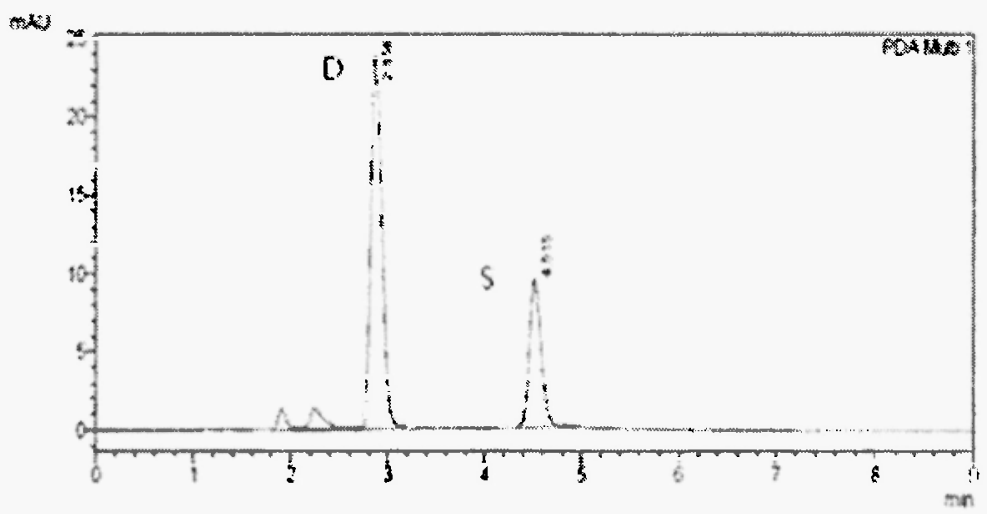

Fig. 8: Sibutramin chromatogram of $15 \mu \mathrm{g} \mathrm{mL}^{-1}$ in plasma

For recovery assays in the plasma, 9 different standards between 5-30 $\mu \mathrm{g}$ $\mathrm{mL}^{-1}$ concentrations from sibutramine stock solution were separately added on $1 \mathrm{~mL}$ of human plasma samples. At the same time, internal standard solution of $1 \mathrm{~mL}$ was added into each of these plasma standards and was completed to $25 \mathrm{~mL}$ with methanol. 


\subsection{Preparation of the Pharmaceutical Samples in Plasma}

Internal standard solution of $1 \mathrm{~mL}$ and $1 \mathrm{~mL}$ of stock solution prepared from sibutramine containing commercial capsule were added on $1 \mathrm{~mL}$ drugfree human plasma sample for HPLC determination. Then, they were diluted with $25 \mathrm{~mL}$ of methanol and in this way; total six commercial capsule standards were prepared.

\subsection{Preparation of Standards in the Plasma with Standard Addition Method}

$1 \mathrm{~mL}$ plasma sample and $2.5,5,7.5,10$ and $12.5 \mu \mathrm{g} \mathrm{mL} \mathrm{m}^{-1}$ from sibutramine stock solution were added into five separate flasks for HPLC determination. Then, parts of $2.5,5,7.5,10$ and $12.5 \mu \mathrm{g} \mathrm{mL}^{-1}$ from commercial capsule stock solution were added into the same flasks and each of the standards reached a total of $15 \mu \mathrm{g} \mathrm{mL}^{-1}$. Also, internal standard solution of $1 \mathrm{~mL}$ was added into the same flasks and then all standards were diluted with methanol. All standards prepared were kept stored in the refrigerator at $4^{\circ} \mathrm{C}$ until used and kept at room temperature before being used. They were ready to be used by mixing for a few minutes by vortex.

\section{RESULTS AND DISCUSSION}

\subsection{Method Validation}

The linearity of the methods was determined by analysis of linear regression with standard calibration curves. Linearity of two methods was obtained over a concentration range from $5-50 \mu \mathrm{g} \mathrm{mL}^{-1}$ for UV and derivative and 5-30 $\mu \mathrm{g} \mathrm{mL}^{-1}$ for HPLC. The correlation coefficients were obtained and the regression equations were calculated as shown in Table I and Table 2 for UV and derivative and in Table 5 for HPLC. The precision of the method, expressed as the relative standard deviation ( $\mathrm{RSD}=100 \mathrm{xSD} / \mathrm{Mean})$ was evaluated. Accuracy was expressed as the mean percentage of analyte recovered in the assay. Both statistical parameters were calculated in each concentration level for the sensitivity of the method. The all RSD values were found as lower than $10 \%$ for all developed methods. LOQ and LOD were calculated using the following equations: $\mathrm{LOQ}=10 . \mathrm{S} / \mathrm{m}, \mathrm{LOD}=3 . \mathrm{S} / \mathrm{m}$ (S is the standard deviation; $m$ is the slope of the calibration curve) as shown in Table 1 and Table 2 for UV and derivative and in Table 5 for HPLC /18/. 


\subsection{UV and Derivative methods}

The spectra are more detailed and sharper with derivatization and thus the bands from the sample matrix and showing the disruptive effects are eliminated. Derivative UV spectrophotometry was preferred for the analysis of sibutramine since amplitude of the signal of derivative spectra was greater the peak shape was well defined and the separation of the peak was better in this method. Based on this, the work involved in the quantification of sibutramine by using derivative spectrophotometry is the first derivative method performed in the literature.

From results obtained for all UV and derivative spectrums, the RSD values in water are smaller than RSD values found in methanol as shown in Table 1 and 2 . It can be said that the precision values in water are higher than the values in methanol. So, the repeatability and the precision are higher in water medium, and RSD, LOQ and LOD values of the second-order derivative are smaller than those of the first-order derivative for both solvent media as shown in the same Tables. The second-order derivative UV spectrum analysis of sibutramine might be more appropriate when compared with the first-order derivative spectrum of sibutramine in both solvent media according to the results in these Tables. As given in Table 3, the recoveries in water are higher than these of methanol and the recoveries of first-order derivative are higher when compared with these of the second-order derivative in both solvent media. According to the results of $t$-test, there is a difference between both solvent media from all spectra results as shown in Table 4. Comparison of the original and first-, second-order derivative spectra of sibutramine in all standards and drug formulation in both solvent media show that the wavelength of maximum absorbance did not change. The impurities did not interfere with the quantitation of sibutramine in capsule.

\subsection{HPLC Method}

For HPLC determination, it has been seen that the features of the calibration curves of sibutramine standard in Table $5(n=6)$. These data indicated that have good linearity in the concentration range of $5-30 \mu \mathrm{g} \mathrm{mL}^{-1}$ and the developed method have a good repeatability both in mobile phase solvent medium and in plasma. Good recoveries were obtained from sibutramine standards and analysis of the commercial capsules in Table 6 and 7. 


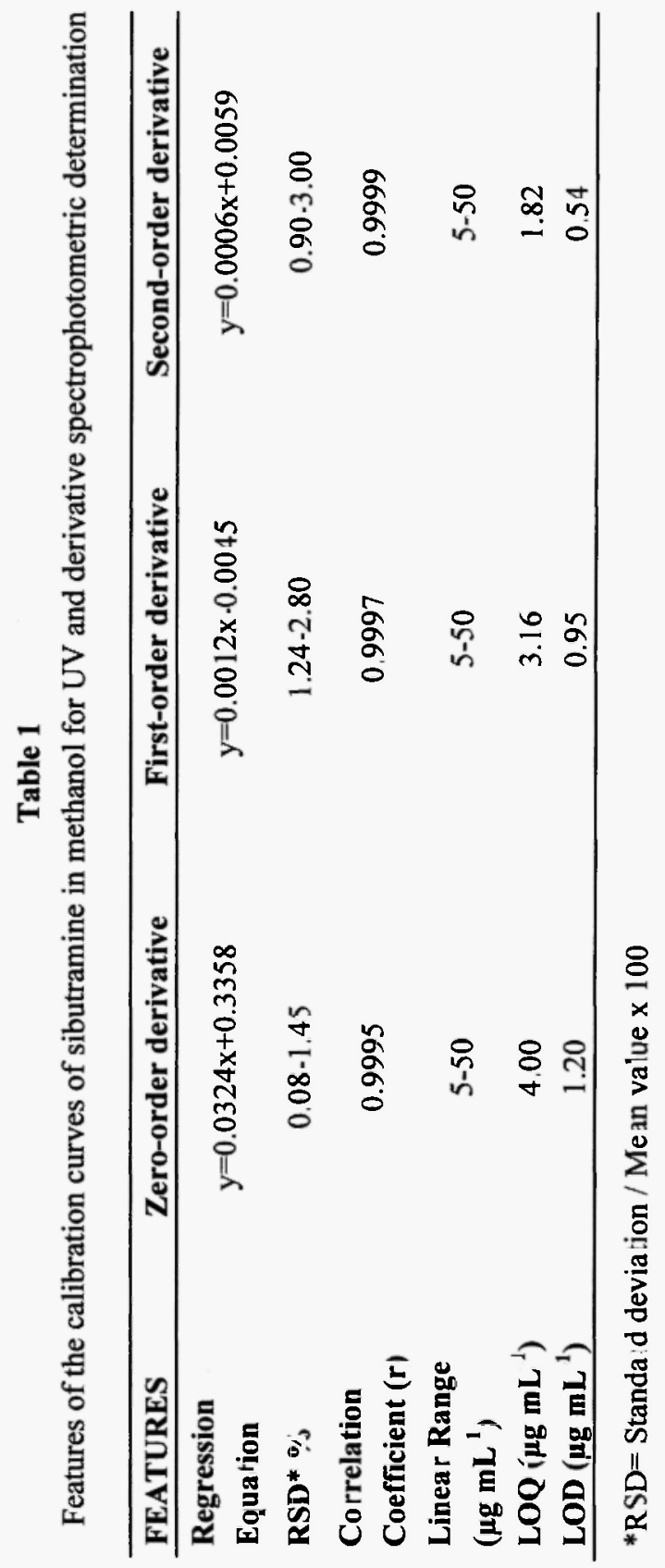




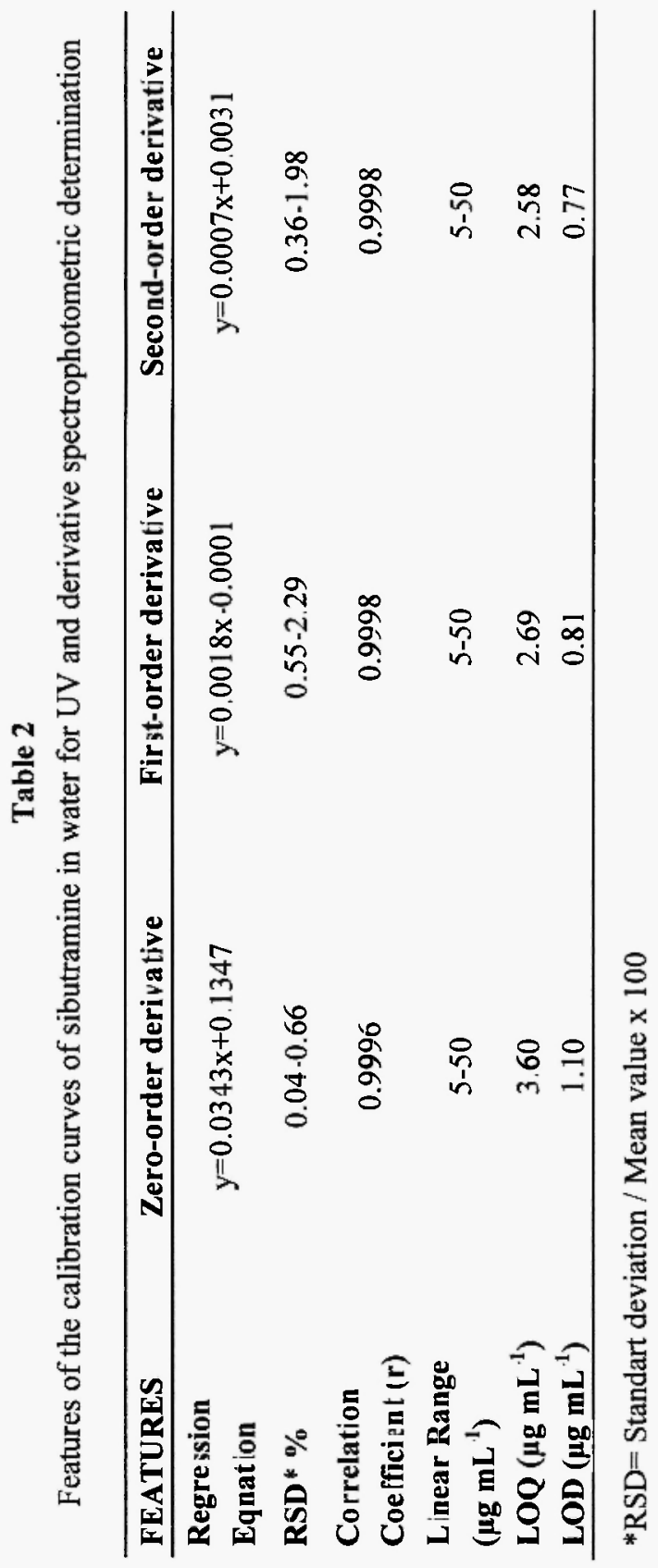




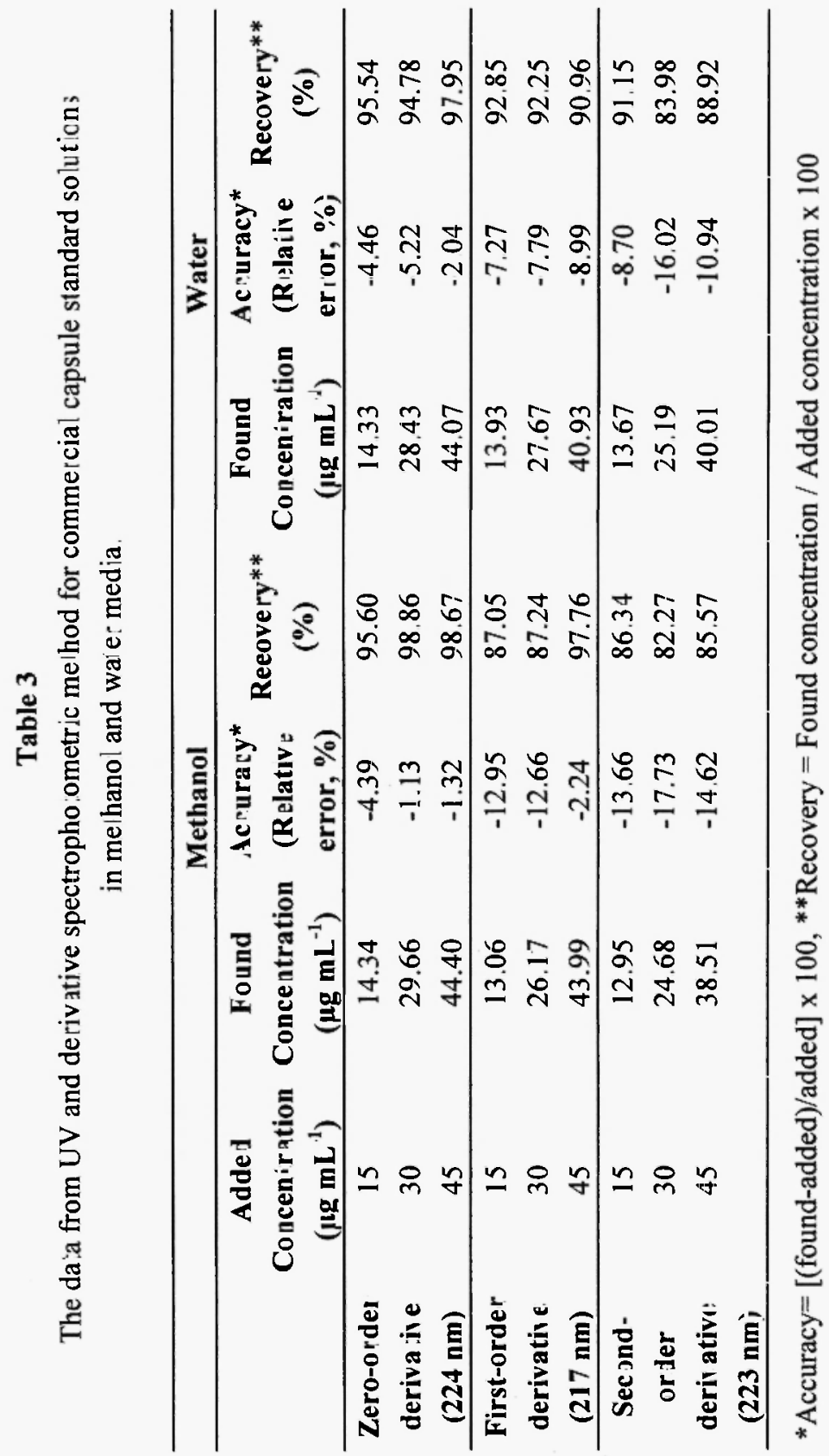




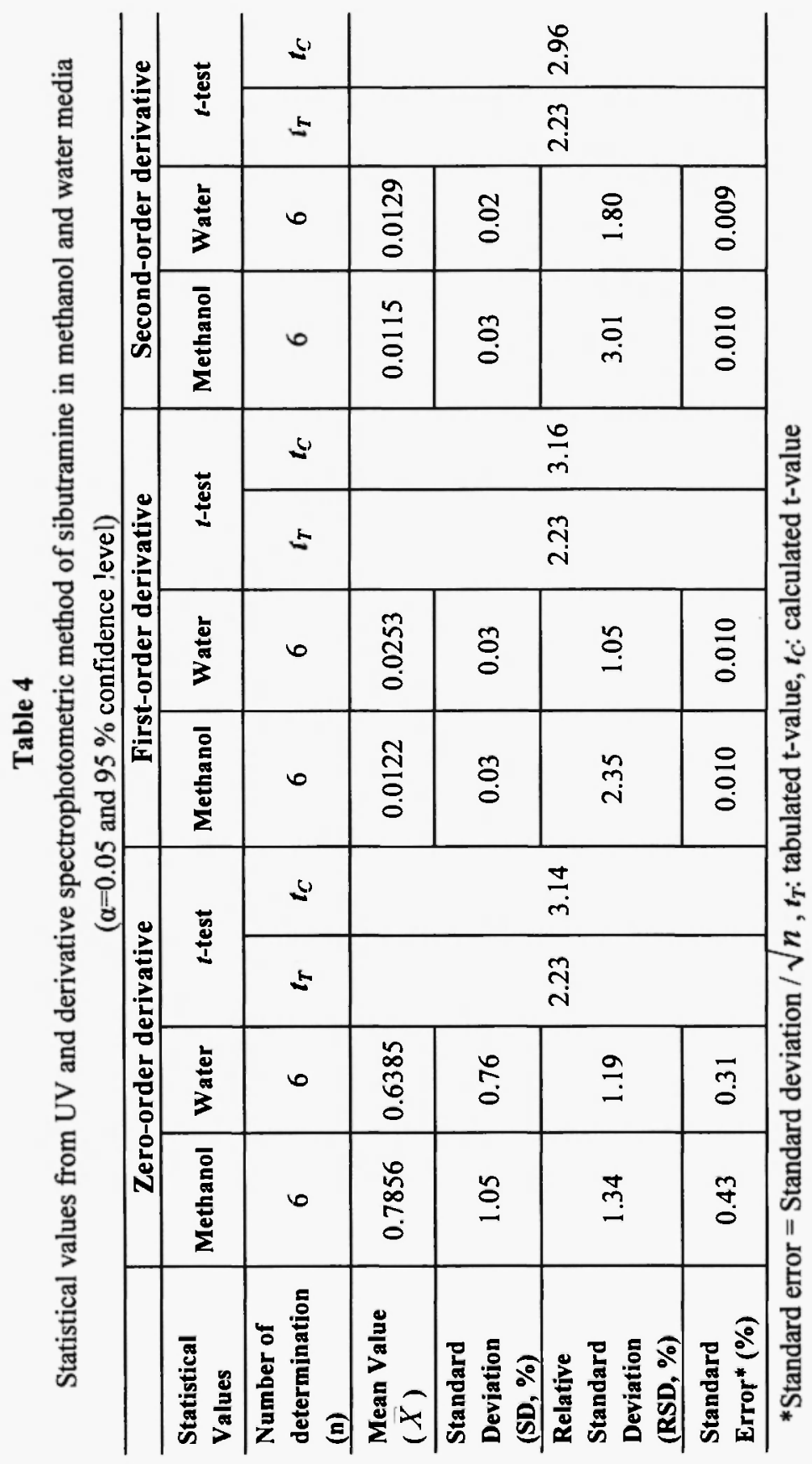




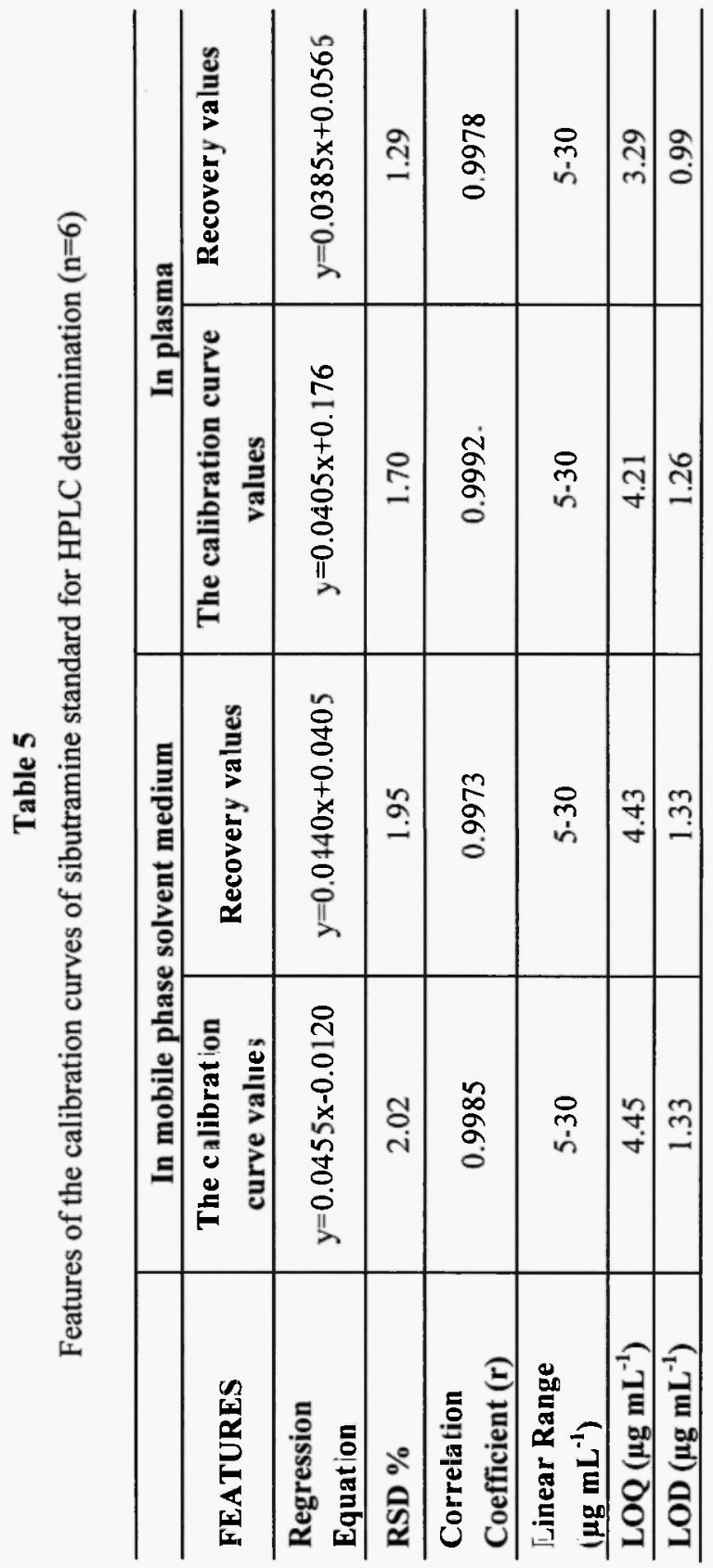




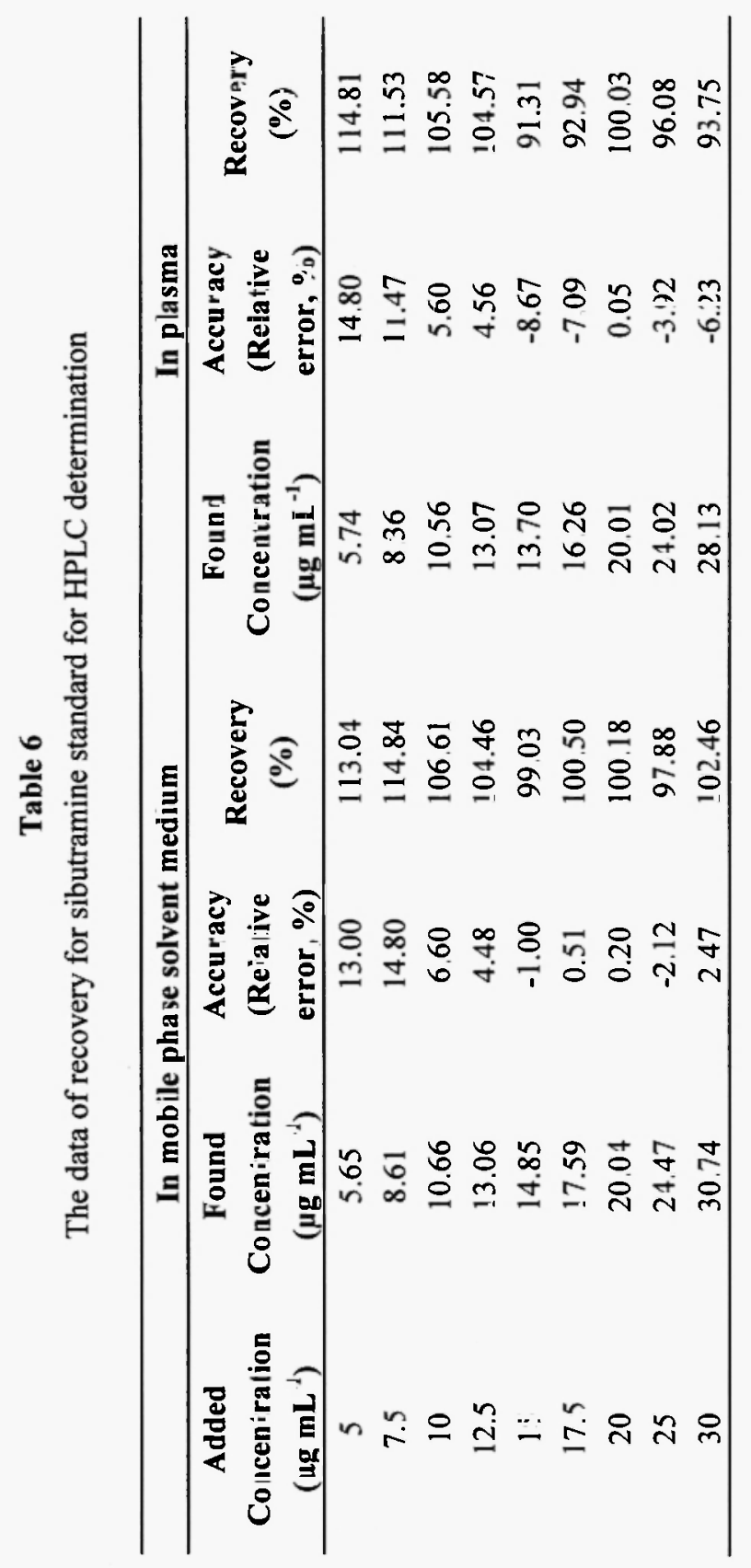




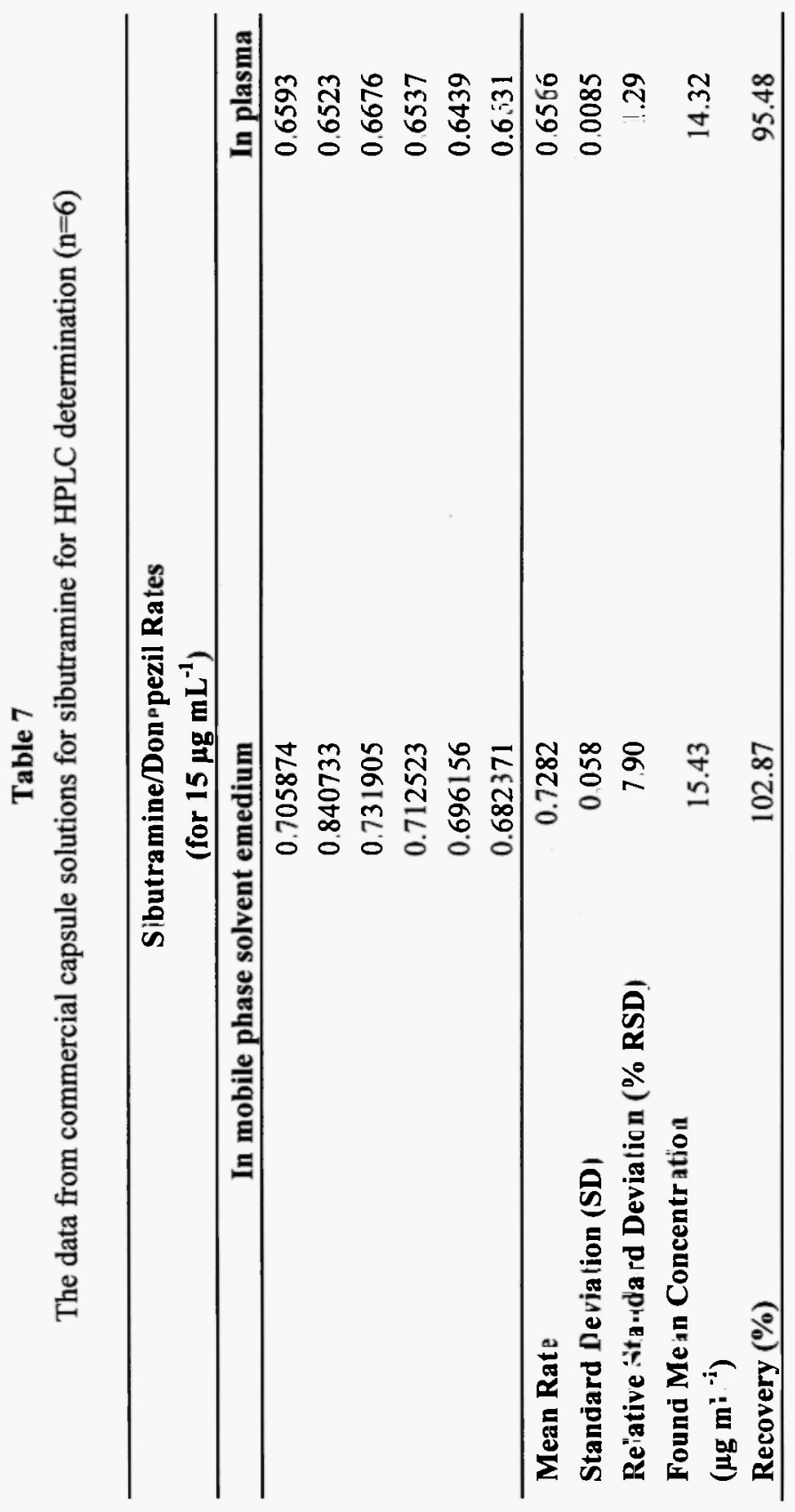




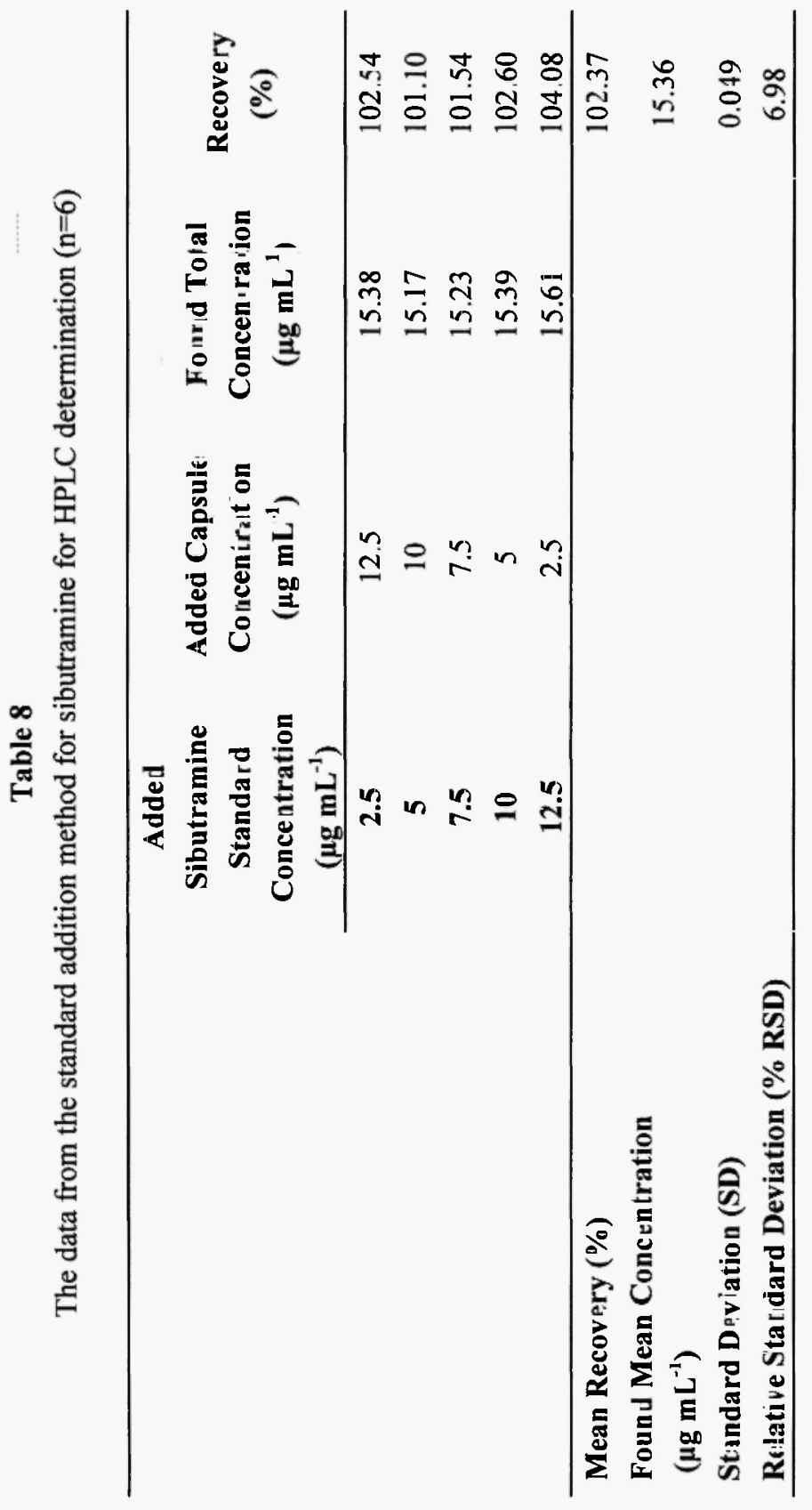




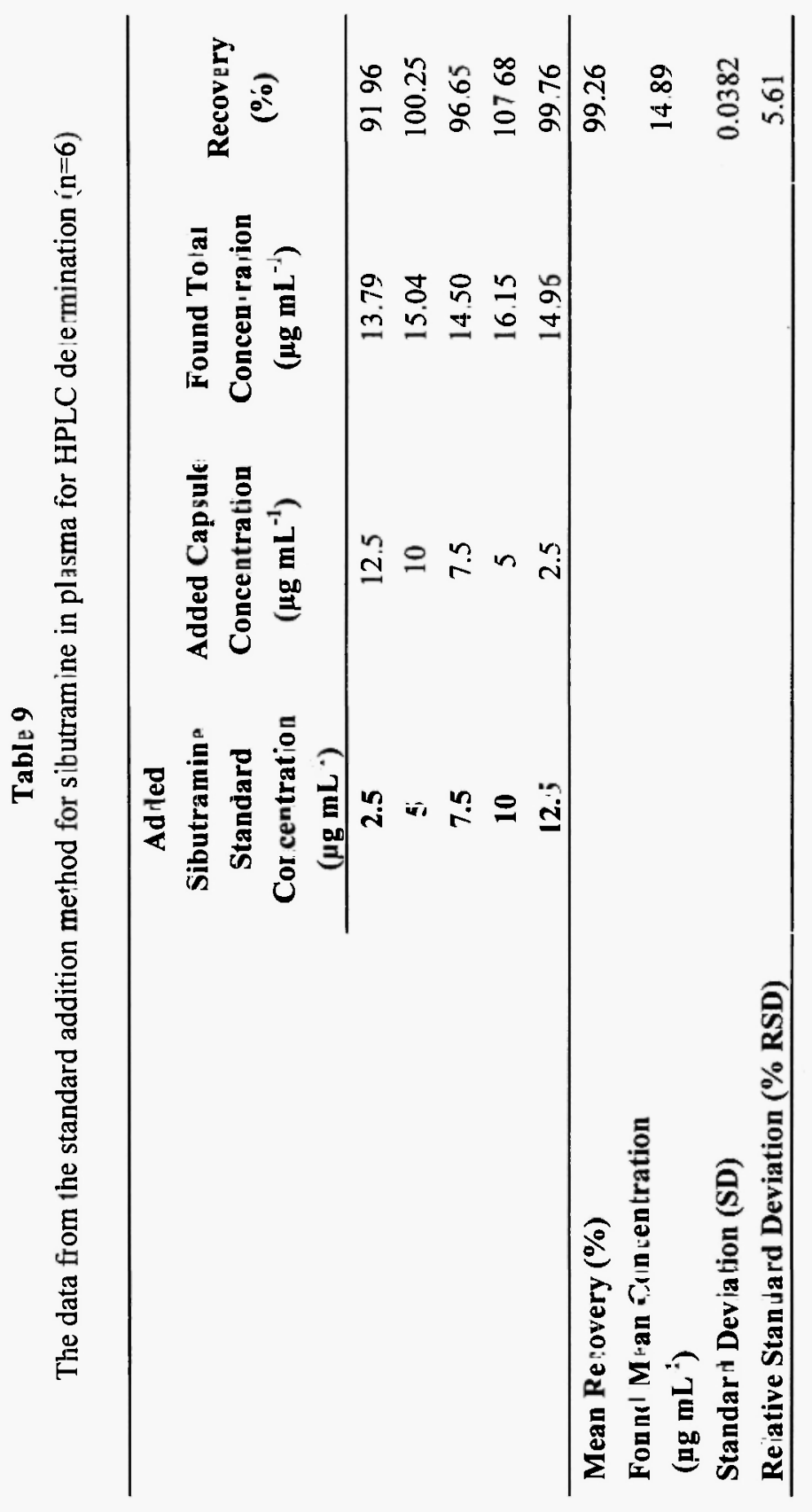


Table 10

Statistical values from in mobile phase solvent medium and in plasma for commercial capsule standard solutions by HPLC method ( $\alpha=0.05$ and $95 \%$ confidence level) $\left(15 \mu \underline{\mathrm{g} \mathrm{mL}} \mathrm{L}^{-1}\right)$

\begin{tabular}{l|c|c|c|c}
\hline Statistical Values & $\begin{array}{l}\text { In mobile phase } \\
\text { solvent medium }\end{array}$ & In plasma & \multicolumn{2}{|c}{$t_{\text {-test }}$} \\
\hline $\begin{array}{l}\text { Number of } \\
\text { determination (n) }\end{array}$ & 6 & 6 & $t_{T}$ & $t_{C}$ \\
\hline $\begin{array}{l}\text { Mean Value } \\
(\bar{X})\end{array}$ & 0.7283 & 0.6566 & & \\
\cline { 1 - 2 } $\begin{array}{l}\text { Standard Deviation } \\
\text { (SD, \%) }\end{array}$ & 5.25 & 0.77 & \multirow{2}{*}{2.23} & \multirow{2}{*}{2.18} \\
$\begin{array}{l}\text { Relative Standard } \\
\text { Deviation } \\
\text { (RSD, \%) }\end{array}$ & 7.21 & 1.18 & & \\
\hline \begin{tabular}{l} 
Standard Error (\%) \\
\hline
\end{tabular} & 2.14 & 0.32 & & \\
\hline
\end{tabular}

Table 11

Statistical comparison of UV and HPLC method for determination of sibutramine in commercial capsule standard solutions ( $\alpha=0.05$ and $95 \%$ confidence level) $\left(15 \mu \mathrm{g} \mathrm{mL}^{-1}\right)$

\begin{tabular}{|c|c|c|c|c|}
\hline Statistical Values & UV & HPLC & \multicolumn{2}{|c|}{$t$-test } \\
\hline Number of determination (n) & 6 & 6 & $t_{T}$ & $t_{C}$ \\
\hline Mean Value $(\bar{X})$ & 0.7856 & 0.7283 & \multirow{4}{*}{2.23} & \multirow{4}{*}{1.91} \\
\hline $\begin{array}{l}\text { Standard Deviation } \\
(\mathrm{SD}, \%)\end{array}$ & 1.05 & 5.25 & & \\
\hline $\begin{array}{l}\text { Relative Standard Deviation } \\
(\mathbf{R S D}, \%)\end{array}$ & 1.34 & 7.20 & & \\
\hline Standard Error (\%) & 0.43 & 2.14 & & \\
\hline
\end{tabular}


The recovery of drug was calculated by comparing the concentration obtained from the spiked mixtures with those of the pure drug. Moreover, to check the validity of the proposed methods, the standard addition method was applied by adding to analyze commercial sibutramine capsules as shown Table 8 and 9. Also, high analytical recoveries from plasma were obtained such as mean $99.26 \%$ with the standard addition method (in Table 9).

To evaluate by comparing statistically plasma levels of developed method was applied all the validation parameters such as the specificity, sensitivity, precision, accuracy, linearity and repeatability and bioanalytical method validation were made. Also the results were evaluated in terms of biostatistics by using statistical Student's $t$-test at a $95 \%$ confidence level. According to the results of $t$-test in Table 10 , it's showed that there is no difference between both media when compared with statistical values obtained from in mobile phase solvent medium and in plasma for commercial capsule standard solutions of $15 \mu \mathrm{g} \mathrm{mL}^{-1}$ by HPLC method ( $\alpha=0.05$ and $95 \%$ confidence level). As shown in Table 11, since $t_{T}$ value is higher than that of $t_{C}$, there is no a significant difference between both methods from all chromatogram results with regard to accuracy and precision. This table summarizes the statistical comparison of the results obtained by applying the proposed UV and HPLC methods. The numerical values of all statistical parameters calculated in Table 11 are in acceptable determination limits in application of two methods to the commercial capsules.

\section{CONCLUSION}

In this study, new UV and derivative spectrophotometric methods were developed and validated for determination of sibutramine in capsule dosage forms in two different solvent media (methanol and water), but also for comparison in two different solvent media. As well as, a new reverse-phase HPLC method with DAD detector was developed and validated to determine the amounts of sibutramine both in commercial capsule preparations and in human plasma (as in vitro). These methods are more simple, rapid and cheaper than some other methods in literature that might be an alternative to some classical methods of existed time-consuming in terms of easily of usage in practice for a routine laboratory. It was obtained high recovery values in plasma without any extraction process thanks to this new alternative method. 
Also, this new alternative reverse-phase HPLC method has some advantages such as a short run time, addition of internal standard and simplicity in plasma studies. Satisfactory results were obtained for drugs and were in good agreement with the label claims. The obtained results were statistically compared with each other as well as those obtained by HPLC method and they showed good agreement.

\section{ACKNOWLEDGEMENTS}

This work is a part of the projects supported by TUBITAK-1002 (109T555) and Sakarya University Scientific Research Projects Commission (2010-50-01-052) entitled 'Quantitative determination in pharmaceutical preparations and biological fluids with spectrophotometric and chromatographic methods of an anti-obesity drug'.

\section{REFERENCES}

1. D.L. Hansen, S. Troubro, M.J. Stock, L.A. Macdonald and A. Astrup, Int. J. Obesity, 23, 1016-1024 (1999).

2. S. Budawari, The Merck Index, 13th Ed. Whitehouse Station, NJ, USA: Merck and Co Inc.; 2001, 1522.

3. D.F. Maluf, P.V. Farago, S.M.W. Barreira, C.F. Pedreso and R. Pontarolo. Validation of an analytical method for determination of sibutramine hydrochloride monohydrate in capsules by UV-Vis spectrophotometry. Latin American Journal of Pharmacy, 26(6): 909912 (2007).

4. I.C.F. Diefenbach, M. Friedrich, C.F. Bittencourt, M.R. Santos and A.L.V. Escarrone. Development and validation of an analytical methodology for determination of sibutramine in capsules. Latin American Journal of Pharmacy, 27(4): $612-617$ (2008).

5. S. Rossi, C. Colamonici and F. Botre Detection of sibutramine administration: A gas chromatography/mass spectrometry study of the main urinary metabolites. Rapid Commun, Mass Spectrom, 21: 79-88 (2007).

6. S. Rossi, C. Colamonici and F. Botre. Parallel analysis of stimulants in 
saliva and urine by gas chromatography/mass spectrometry: Perspectives for in competition anti doping analysis. Analytica Chimica Acta, 606: 217-222 (2008).

7. L. Ding, X. Hao, X. Huang and S. Zhang. Simultaneous determination of sibutramine and its n-desmethyl metabolites in human plasma by liquid chromatography-electrospray ionization-mass spectrometry Method and clinical applications. Analytica Chimica Acta, 492: 241-248 (2003).

8. Z.Q. Huanng, S. Xiao, D. Luo, B. Chen and S.Z. Yao. Simultaneous determination of sibutramine and $\mathrm{N}$-Di-desmethylsibutramine in dietary supplements for weight control by HPLC-ESI-MS. Journal of Chromatographic Science, 46(8): $707-711$ (2008).

9. J. Chen, W. Lu, Q. Zhang and X. Jiang. Determination of the active metabolite of sibutramine by liquid chromatography-electrospray ionization tandem mass spectrometry. Journal of Chromatography B, 785: 197-203 (2003).

10. D.S. Jain, G. Subbaiah, M. Sanyal, P.S. Shrivastav, U. Pal, S. Ghataliya, A. Kakad, H. Patel and S. Shah. Liquid chromatography/electrospray ionization tandem mass spectrometry validated method for the simultaneous quantification of sibutramine and its primary and secondary amine metabolites in human plasma and its application to a bioequivalence study. Rapid Communications in Mass Spectrometry. 20: 3509-3521 (2006).

11. J. Bhatt, B. Shah, S. Kamli, G. Subbaiah, S. Singh and S. Ameta. Rapid and sensitive method for the determination of sibutramine active metabolites in human plasma by reversed-phase liquid chromatographytandem mass spectroscopy. Journal of Chromatographic Science, 45(2): 91-96 (2007).

12. A.I. Segall, E.A. Collada, R.A. Ricci and M.T. Pizzorno. Reversedphase HPLC determination of sibutramine hydrochloride in the presence of its oxidatively-induced degradation products. Journal of Liquid Chromatography \& Related Technologies. 26(6): 977-986 (2003).

13. J.G. Chandorkar, V.B. Kotwal, N.S. Dhande, M.P. Pachpor and V.V. Pande. Development and validation of high performance liquid chromatography method for analysis of sibutramine hydrochloride and its impurity. Pakistan Journal of Pharmaceutical Sciences, 21(2): 121124 (2008). 
14. A.P. Suthar, S.A. Dubey and S.R. Patel. A validated specific reverse phase liquid chromatographic method for the estimation of sibutramine hydrochloride monohydrate in bulk drug and capsule dosage forms. International Journal of Chemtech Research, 1(4): 793-801 (2009).

15. I.C.F. Diefenbach, M. Friedrich, M.R. Dos Santos and C.F. Bittencourt. Development and validation of a column high-performance liquid chromatographic method for determination of sibutramine in capsules. Latin American Journal of Pharmacy, 92(1): 148-151 (2009).

16. T. Radhakrishna, Ch. Lakshmi Narayana, D. Sreenivas Rao, K. Vyas and G.Om. Reddy. LC method for the determination of assay and purity of sibutramine hydrochloride and its enantiomers by chiral chromatography. Journal of Pharmaceutical and Biomedical Analysis, 22: 627-639 (2000).

17. S.Y. Um, K.B. Kim, S.H. Kim, Y.C. Ju, H.S. Lee, H.Y. Oh, K.H. Choi and M.W. Chung. Determination of the active metabolites of sibutramine in rat serum using column-switching hplc. Journal of Separation Science, 31: 2820-2826 (2008).

18. Reviewer Guidance: Validation of Chromatographic Methods, Centre for Drug Evaluation and Research (CDER), Food and Drug Administration, November 1994. 
